\title{
INTEGRASI PENCEMARAN LOGAM BERAT DAN ISLAM MENGGUNAKAN METODE 4-STMD
}

\author{
Munasprianto Ramli, Buchori Muslim, Silvi Nur Fajriah \\ Universitas Islam Negeri Syarif Hidayatullah Jakarta, Ciputat, Tangerang Selatan \\ Email: silvinurfajriahfajriah@gmail.com
}

\begin{abstract}
The suggestion of integration of science arises because of the dichotomy or separation between the religious sciences and other general sciences. The development of the scientific integration movement, especially religion and science, The State Islamic University Syarif Hidayatullah Jakarta was present to carry out this scientific integration movement. The purpose of this research is to analyze aspects of Islamic integration in the form of Al-Qur'an, hadiths, fiqh, verses of kauniyah and Islamic history with chemistry on heavy metal pollution material using the 4S-TMD method. The 4S-TMD method is carried out using four stages that must be taken, which consist of selection, structuring, characterization, and reduction. At the selection stage, there are 15 Islamic integrated chemical concepts were found. In the structuring phase, 6 main concepts of Islamic integrated chemistry were obtained. At the characterization stage, the results showed that most of the material concepts contained in the teaching material were classified as easy concepts, with a percentage of writing the main idea of $94.72 \%$ and the qualification of 2015 student understanding at The State Islamic University Syarif Hidayatullah Jakarta on the concept integrated categorized as good. Researchers do not use the reduction stage because the level of understanding of students is good. The concepts of integrated Islamic chemistry are expected to help the process of plug in Islamic learning in the chemical education study program at The State Islamic University Syarif Hidayatullah Jakarta.
\end{abstract}

Keywords: Integration of Islam and Science, 4-STMD Method

\begin{abstract}
Abstrak: Gagasan integrasi ilmu muncul karena adanya dikotomi atau pemisahan antara ilmu-ilmu agama dengan ilmu-ilmu umum lainnya. Seiring dengan perkembangan gerakan integrasi keilmuan khususnya ilmu agama dan sains maka Universitas Islam Negeri Syarif Hidayatullah Jakarta hadir untuk melakukan gerakan integrasi keilmuan ini. Adapun tujuan dari penelitian ini yaitu menganalisis aspek integrasi Islam berupa Al-Qur'an, hadist, fiqih dan usul fiqih, ayat kauniyah dan sejarah Islam dengan ilmu kimia pada materi pencemaran logam berat menggunakan metode 4S-TMD (Four Step Teaching Material Development). Metode 4S-TMD ini dilakukan dengan menggunakan empat tahap yang harus ditempuh, yang terdiri dari seleksi, strukturisasi, karakterisasi, dan reduksi. Pada tahap seleksi didapatkan 15 konsep kimia terintegrasi keislaman. Pada tahap strukturisasi didapatkan 6 konsep utama kimia terintegrasi keislaman. Pada tahap karakterisasi didapatkan hasil menunjukkan sebagian besar konsep-konsep materi yang terdapat pada bahan ajar tergolong konsep mudah, dengan persentase penulisan ide pokok sebesar 94,72\% dan kualifikasi pemahaman mahasiswa angkatan 2015 di Universitas Islam Negeri (UIN) Syarif Hidayatullah Jakarta terhadap konsep yang terintegrasi dikategorikan baik. Peneliti tidak menggunakan tahap reduksi dikarenakan tingkat keterpahaman mahasiswa sudah baik. Konsep-konsep kimia terintegrasi keislaman ini diharapkan dapat membantu proses pembelajaran terintegrasi keislaman pada program studi pendidikan kimia Universitas Islam Negeri (UIN) Syarif Hidayatullah Jakarta.
\end{abstract}

Kata Kunci: Integrasi Islam dan Sains, Metode 4-STMD

\section{PENDAHULUAN}

Pada tahun 2002 pemerintah memberi izin pertama kali untuk melakukan perubahan dari Institut Agama Islam Negeri (IAIN) Syarif Hidayatullah Jakarta menjadi Universitas Islam Negeri (UIN) Syarif Hidayatullah Jakarta dengan keputusan Presiden 
Nomor 31. Transformasi kelembagaan pendidikan tinggi Islam menjadi universitas merupakan sarana untuk mengintegrasikan ilmu-ilmu agama dengan ilmu-ilmu lainnya (Pedoman Implementasi Integrasi Ilmu di PTKI, 2019). Integrasi dimaknai bagian yang utuh yang tidak terpisah sehingga menjadi kolaborasi yang utuh. Adapun pengertian lain dari kata integrasi yaitu penggabungan beberapa hal menjadi kesatuan yang utuh dan tidak dapat dipisahkan (Iskandar, 2016: 87).

Semenjak abad ke 17 telah terjadi perubahan pemikiran para filsuf tentang memisahkan antara pengetahuan dan niai-nilai agama (Tajuddin, dan Rofie, 2014). Pembahasan tentang pengintegrasian Islam dan sains berawal dari perdebatan di kalangan cendekiawan muslim. Beberapa berpendapat tidak adanya hubungan yang jelas antara sains dan agama Islam (Munadi, 2016). Hingga saat ini masyarakat luas masih beranggapan bahwa "ilmu" dan "agama", "sekolah" dan "madrasah" merupakan suatu hal yang terpisah (Jamal, 2017). Topik integrasipun menjadi menarik untuk didiskusikan oleh masyarakat dan akademis sampai saat ini. Maka dari itu Perguruan Tinggi Islam memiliki peranan penting dalam mengintegrasikan ilmu-ilmu agama dengan ilmu-ilmu lainnya.

Setiap Universitas Islam Negeri (UIN) memiliki konsep integrasi yang berbedabeda. Adapun konsep integrasi ilmu di Universitas Islam Negeri (UIN) Syarif Hidayatullah Jakarta yaitu, integrasi keilmuan merupakan perpaduan antara ilmu agama dan ilmu umum. Perpaduan ini mencakup beberapa aspek yaitu, 1) integrasi ontologis, 2) integrasi klasifikasi ilmu dan 3) integrasi metodologis (Rifai, Fauzan, Sayuti, dan Bahrissalim, 2014). Adapun visi misi Universitas Islam Negeri (UIN) Syarif Hidayatullah Jakarta yaitu "menjadikan universitas kelas dunia dengan keunggulan integrasi keilmuan, keislaman, dan keindonesiaan" (Keputusan Rektor UIN Jakarta No. 864 Tahun 2017). Untuk mewujudkan amanaat integrasi ini maka perlu dilakukan proses pembelajaran terintegrasi di setiap program studi Universitas Islam Negeri (UIN) Syarif Hidayatullah Jakarta.

Ujung tombak pendidikan tinggi terletak pada eksistensi program studi dalam menjalankan berbagai aktifitas akademik atau non akademik yang mengarah pada peningkatan mutu lulusan pendidikan (Fauzan, 2017). Maka dari itu setiap program studi berhak menentukan capaian pembelajaran (Course Learning Outcome) yang akan dicapai oleh mahasiswa berdasarkan visi misi setiap universitas (Permenristekdikti No.44 Tahun, 2015). Proses pembelajaran terintegrasi keislaman salah satunya dapat dilakukan pada 
jurusan pendidikan kimia pada mata kuliah kimia lingkungan. Adapun bagian dari materi kimia lingkungan yang memiliki integrasi keislaman salah satunya tentang materi pencemaran logam berat.

Pencemaran logam berat terhadap lingkungan erat hubungannya dengan eksploitasi logam berat itu sendiri. Seiring meningkatnya proses industrialisasi yang menggunakan logam berat, maka pencemaran logam beratpun cenderung meningkat. Pencemaran logam berat dapat menimbulkan kerusakan lingkungan, baik di lingkungan udara, air, dan tanah (Widowati, Sastiono dan Jusuf, 2008). Ayat mengenai kerusakan lingkunganpun telah dijelaskan pada Q.S Ar-Rum ayat 41 yang berbunyi:

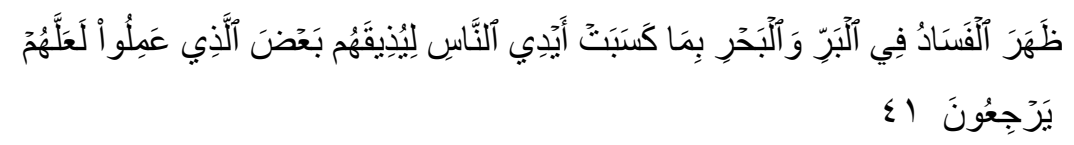

Artinya: Telah nampak kerusakan di darat dan di laut disebabkan karena perbuatan tangan manusia, supaya Allah merasakan kepada mereka sebagian dari (akibat) perbuatan mereka, agar mereka kembali (ke jalan yang benar).

Arti dan tafsiran ayat diatas sesuai dengan kondisi sekarang dimana telah tampak kerusakan di darat dan di laut, baik kota maupun desa, disebabkan karena perbuatan tangan manusia yang dikendalikan oleh hawa nafsu dan jauh dari tuntunan fitrah. Allah menghendaki agar mereka merasakan sebagian dari akibat perbuatan buruk mereka, agar mereka kembali ke jalan yang benar dengan menjaga kesesuaian perilakunya dengan fitrahnya (Shihab, 2012).

Untuk mewujudkan proses pembelajaran terintegrasi keislaman pada materi pencemaran logam berat, maka dibutuhkan suatu metode yang dapat menganalisis konsep-konsep kimia yang memiliki integrasi keislaman. Metode yang dapat digunakan yaitu 4-STMD (Four steps teaching material development). Metode ini memiliki 4 tahapan yaitu, seleksi, strukturisasi, karakterisasi, dan reduksi. Adapun tahap mengaanalisis konsep integrasi terdapat pada tahap seleksi. Pada tahap seleksi konsepkonsep kimia yang telah terintegrasi keislaman akan diberikan kepada validator ahli untuk mengetahui kebenaran dari konsep-konsep kimia yang telah terintegrasi keislaman (Syamsuri, Anwar, dan Sumarna 2017). Maka dari itu metode ini dapat digunakan untuk melahirkan konsep-konsep kimia terintegrasi keislaman kedepannya.

\section{LANDASAN TEORI}

Metode 4-STMD (Four steps teaching material development) terdiri atas 4 tahapan yaitu seleksi, strukturisasi, karakterisasi, dan reduksi (Syamsuri, Anwar, dan Sumarna 
2017). Tahap seleksi merupakan tahap mengumpulkan informasi yang diperlukan yang berhubungan dengan materi yang akan dikembangkan (Arifin, 2015:10). Menurut (Hendri dan Setiawan, 2016) tahap seleksi terdiri atas lima tahapan, 1) Menyeleksi sumber literatur yang akan digunakan, 2) Analisis course learning outcome (CLO) serta pengembangan Indikator yang merujuk pada rencana pembelajaran semester (RPS) pada materi pencemaran logam berat,3) Analisis konsep, 4) Analisis aspek integrasi keislaman yang terkait pada materi pencemaran logam berat, 5) Validasi konten oleh validator.

Tahap strukturisasi adalah tahapan yang dilakukan agar peserta didik dapat mengetahui hubungan satu konsep dengan konsep lainnya, dan dapat menggambarkan sistematika penyajian bahan ajar (Arifin, 2015:12). Menurut (Hendri dan Setiawan, 2015) tahap strukturisasi terdiri atas beberapa tahapan, diantaranya: 1) membuat peta konsep, 2) membuat struktur makro, 3) membuat draft bahan ajar. Sedangkan tahap yang ketiga yaitu tahap karakterisasi merupakan tahapan untuk mengetahui tingkat keterpahaman peserta didik mengenai konsep yang yang telah dikembangkan. Pada tahap ini dikembangkan instrumen yang akan diuji cobakan kepada peserta didik, lalu konsepkonsep tersebut diidentifikasi untuk mengetahui tingkat keterpahaman peserta didik (Hendri \& Setiawan, 2016: 68). Tahap yang keempat yaitu tahap reduksi, menurut (Ashri dan Hasanah, 2016) reduksi merupakan tahapan untuk mengurangi tingkat kesulitan bahan ajar, sehingga bahan ajar dapat lebih dipahami oleh peserta didik.

\section{METODOLOGI}

Penelitian pengembangan ini mengikuti tahapan penelitian dengan metode 4-STMD (Four steps teaching material development). Alur penggunaan metode ini dapat dilihat pada gambar dibawah ini.

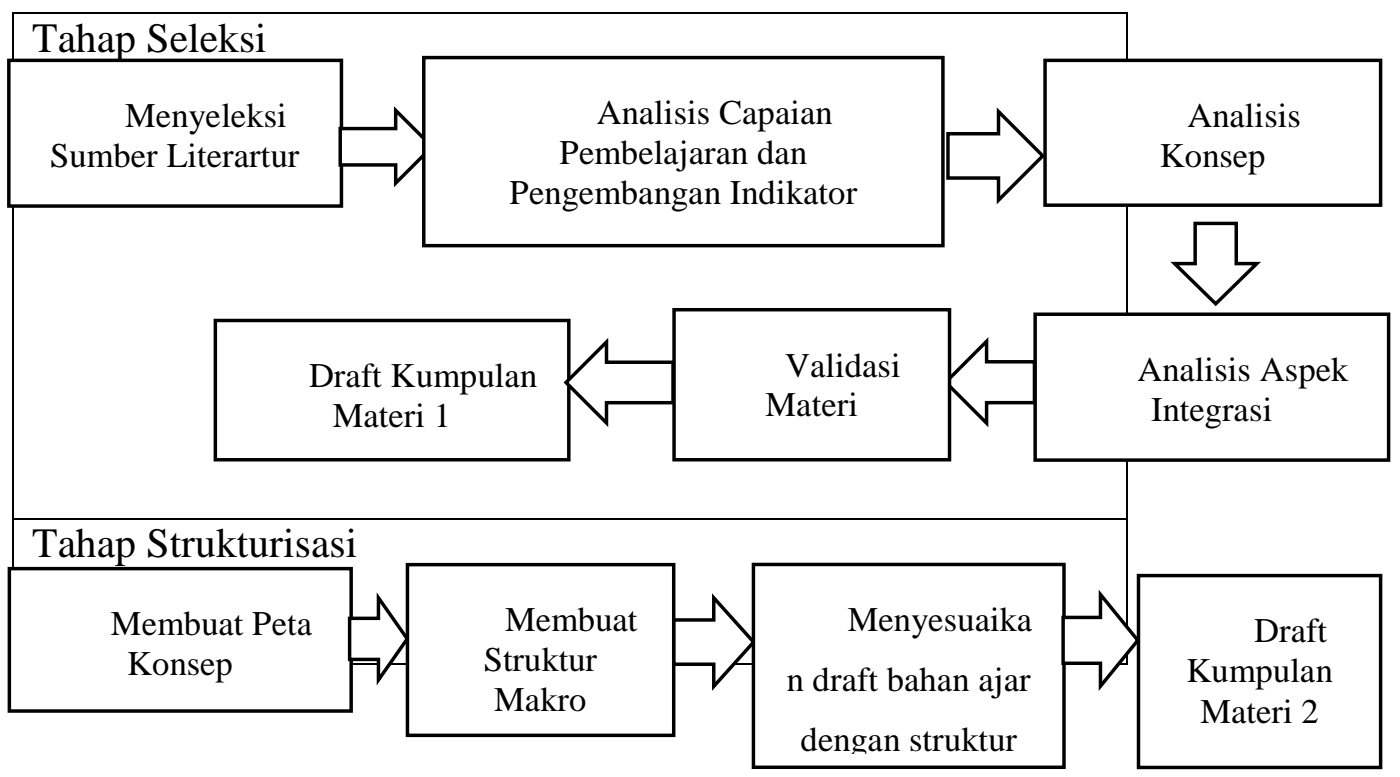




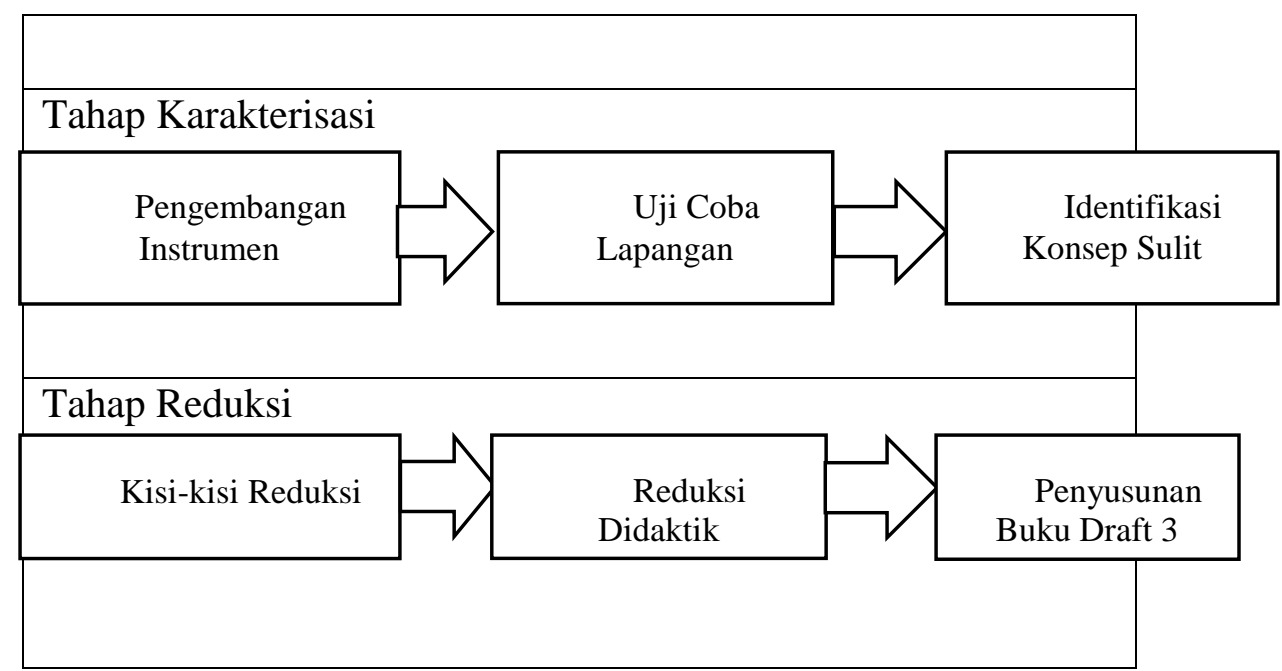

Gambar 1 Alur Penelitian

Objek pada penelitian yaitu berupa buku pengayaan kimia terintegrasi keislaman. Buku pengayaan ini diambil dari buku rujukan dengan topik kajian yang mendukung penelitian ini, dan buku yang dibuat oleh peneliti yang didampingi oleh dua dosen pembimbing Universitas Islam Negeri Syarif Hidayatullah Jakarta. Buku pengayaan ini memiliki penjelasan mengenai integrasi pencemaran logam berat dengan keislaman. Adapun subjek dalam penelitian ini yaitu mahasiswa program studi pendidikan kimia Universitas Islam Negeri Syarif Hidayatullah Jakarta angkatan 2015, dengan responden sebanyak 72 mahasiswa. Instrumen yang digunakan pada uji keterpahaman adalah berupa soal pilihan ganda yang disusun dari bahan ajar. Data yang diperoleh dari uji keterpahaman merupakan data dikotomi dengan sistem penilaian 1 (satu) untuk jawaban benar dan 0 (nol) untuk jawaban yang salah. Setiap butir soal kemudian dihitung persentasinya menggunakan persamaan 1 berikut ini:

$$
\% \text { item }=\frac{\text { skor perolehan }}{\text { skor total }} \times 100
$$

Setelah melakukan pengolahan data persentase yang didapatkan dapat digolongkan kedalam persentase keterpahaman bahan menurut Rankin dan Chulhane yang dikutip oleh Ashri dkk, (Ashri, Nurul., \& Hasanah, Lilik, 2016).

Tabel 1 Persentase keterpahaman bahan ajar menurut Rankin dan Chulhane

\begin{tabular}{ll}
\hline Persentase & Tingkat Keterpahaman \\
\hline$\geq 60 \%$ & Tinggi \\
$\geq 41-60 \%$ & Sedang \\
$\leq 41 \%$ & Rendah \\
\hline
\end{tabular}




\section{PEBAHASAN DAN HASIL}

A. Tahap Seleksi

Pada tahap seleksi terdapat beberapa tahapan yaitu 1) penyeleksian referensi, 2) analisis capaian pembelajaran, 3) analisis konsep, dan 4) analisis aspek integrasi. Berikut temuan dari tahapan tersebut.

\section{Tahap penyeleksian referensi}

Tahap pertama dari metode 4-STMD adalah tahap penyeleksian referensi, dalam tahap ini didapatkan 1 sumber utama yaitu buku yang ditulis Wahyu Widowati tahun 2008 terbitan C.V Andi Ofset Yogyakarta dengan judul Efek Toksik Logam Pencegahan dan Penanggulangan Pencemaran. Buku ini dipilih sebagai buku utama dikarenakan memiliki konsep yang cukup lengkap mengenai pencemaran logam berat. Selain buku utama terdapat 10 referensi buku penunjang utama.

2. Tahap analisis capaian pembelajaran

Pada tahap ini peneliti menganalisis capian pembelajaran berupa course learning outcome (CLO) yang akan dicapai oleh mahasiswa dengan materi yang akan diintegrasikan. Pada tahap Analisis Capaian Pembelajaran terdapat 16 capaian pembelajaran yang akan dicapai oleh mahasiswa angkatan 2015 Universitas Islam Negeri Syarif Hidayatullah Jakarta, 16 Capaian pembelajaran ini mencakup capaian pembelajaran dalam bentuk ranah kognitif. Berikut materi dan course leraning outcome yang dapat dilihat pada Tabel dibawah ini.

Tabel 2 Materi dan course learning outcome

\begin{tabular}{ll}
\hline Materi & Course Learning Outcome \\
\hline Logam berat & Mengetahui pencemaran logam berat dan jenis \\
& logam berat \\
Logam berat esensial & Menjelaskan sifat logam berat esensial \\
Logam berat tidak esensial & Menjelaskan sifat logam berat tidak esensial \\
Kegunaan logam berat & Menjabarkan kegunaan logam berat \\
Sumber pencemaran logam berat & Menemukan sumber pencemaran logam berat \\
Kegiatan manusia & Membuktikan sumber pencemaran logam berat dari \\
& kegiatan manusia \\
Alami & Membuktikan sumber pencemaran logam berat yang \\
Daerah pencemaran logam & berasal dari Alam berat \\
& Merumuskan daerah pencemaran logam beran \\
\hline
\end{tabular}




\begin{tabular}{ll}
\hline Air & Menganalisis jenis air yang telah tercemar logam \\
Tanah & berat berdasarkan perspektif Islam \\
& Menemukan pencemaran logam berat dalam tanah \\
& yang bersifat merugikan terhadap manusia, hewan, \\
& dan tumbuhan \\
& Menemukan pencemaran logam berat dalam udara \\
Udara & Mengkaji masalah yang timbul akibat efek toksik \\
Efek toksik logam berat & logam berat \\
& Mengkaji masalah yang timbul dari pencemaran \\
Keracunan mahluk hidup & logam berat terhadap keracunan mahluk hidup \\
Karsinogenik & Mengkaji masalah karsinogenik akibat pencemaran \\
Penyakit minamata & logam berat \\
& Mengkaji masalah penyakit minamata yang \\
Penanggulangan pencemaran logam & disebabkan oleh pencemaran logam berat \\
berat & Menemukan cara menanggulangi pencemaran logam \\
\hline
\end{tabular}

\section{Tahap analisis konsep}

Menurut (Herron et al., 1977) analisis konsep yang dibuat oleh peneliti dikemas dalam bentuk peta konsep. Peta konsep terdiri atas 1) label konsep, 2) definisi konsep, 3) jenis konsep, 4) atribut konsep yang terdiri atas a) atribut kritis dan b) atribut variabel, 5) posisi konsep yang terdiri atas a) superordinat, b) koordinat, dan c) subordinat, d) contoh dan e) noncontoh. Peneliti membuat isi dari peta konsep agar mempertahankan kemurnian konsep dan menghindari miskonsepsi.

4. Tahap analisis aspek integrasi keislaman.

Terdapat 5 aspek keislaman yang diintegrasikan dengan materi pencemaran logam berat. Pertama, Al-Qur'an. Al-Qur'an mengungkapkan tanda-tanda ilahi serta menunjukkan kuasa ilahi supaya manusia sadar akan keberadaan Tuhan. Hal-hal ilmiah yang terdapat dalam Al-Qur'an sudah terbukti dengan teori-teori yang ada (tidak menyimpang) (Bagheri, 2015; Sudiarti, 2018; Suhendar, 2011). Kedua, Hadist. Dalam sains Islam, konstruksi sains dapat bersumber dari Al-Qur'an dan Hadist yang dilanjutkan dengan observasi alam (Yusuf, 2017). Ketiga, Ilmu Fiqih, menurut Al-Faruqi dalam Akbarizan kaidah fikih dapat menentukan sains secara hukum Islam (Al-Faruqi dalam Akbarizan, 2014). Aspek integrasi yang keempat yaitu, ayat qauliyah dan kauniyah, 
Suprayogo menyatakan untuk memahami kehidupan dan alam semesta ini dibutuhkan ayat qauliyah dan ayat kauniyah. Ayat qauliyah yaitu bersumber dari Al-Qur'an dan Hadist, dan ayat kauniyah merupakan tanda-tanda atau fenomena alam yang terjadi (Suprayogo, 2012). Dalam mengembangkan ilmu pengetahuan perguruan tinggi Islam hendaknya mengambil sumber kepada ayat-ayat qauliyah dan kauniyah. Oleh karena itu kedua sumber tersebut harus memiliki perspektif yang positif terhadap ragam ilmu pengetahuan yang ada. Aspek yang kelima yaitu Sejarah Islam, pengintegrasian ilmu harus diterangkan dengan jelas seperti yang terjadi dalam sejarah (Al-Faruqi dalam Akbarizan, 2014).

Pada tahap analisis aspek integrasi didapatkan 15 dari 16 konsep kimia terintegrasi keislaman yang telah tervalidasi oleh ahli materi. Terdapat 1 konsep yang tidak disetujui oleh validator karena menurut validator konsep tersebut tidak memiliki integrasi keislaman. Adapun konsep yang tidak disetujui oleh validator yaitu konsep sumber pencemaran logam berat.

Tabel 3 Analisis Aspek Integrasi

\begin{tabular}{|c|c|c|}
\hline Materi & Indikator & Integrasi Keislaman \\
\hline Berat & $\begin{array}{l}\text { Mengetahui } \\
\text { pencemaran logam } \\
\text { berat dan jenis } \\
\text { logam berat }\end{array}$ & $\begin{array}{l}\text { Al-Qur'an } \\
\text { Menjelaskan mengenai kerusakan } \\
\text { lingkungan baik di daratan maupun di } \\
\text { lautan. Pencemaran logam berat adalah } \\
\text { salah satu hal yang dapat merusak } \\
\text { kerusakan lingkungan, dan Allah tidak } \\
\text { menyukai orang yang berbuat kerusakan. }\end{array}$ \\
\hline Logam Berat & Menjelaskan sifat & $\underline{\text { Sejarah Islam }}$ \\
\hline Tidak Esensial & $\begin{array}{l}\text { logam berat non } \\
\text { esensial }\end{array}$ & $\begin{array}{l}\text { Menjelaskan mengenai logam berat non } \\
\text { esensial dapat berubah menjadi racun, dan } \\
\text { racun telah ada sejak zaman Nabi } \\
\text { Muhamad SAW. }\end{array}$ \\
\hline Alami & $\begin{array}{l}\text { Membuktikan } \\
\text { sumber pencemaran } \\
\text { logam berat dari } \\
\text { Alam }\end{array}$ & $\begin{array}{l}\text { Ayat Kauniyah (Fenomena Alam) } \\
\text { Menjelaskan mengenai pencemaran logam } \\
\text { berat yang bersumber dari alam, dapat } \\
\text { terjadi karena fenomena alam seperti debu- } \\
\text { debu dari kegiatan gunung merapi. }\end{array}$ \\
\hline
\end{tabular}




\begin{tabular}{|c|c|c|}
\hline \multirow[t]{2}{*}{ Air } & Menganalisis jenis & $\underline{\text { Fiqih dan Usul Fiqih }}$ \\
\hline & $\begin{array}{l}\text { air yang telah } \\
\text { tercemar logam } \\
\text { berat berdasarkan } \\
\text { perspektif Islam }\end{array}$ & $\begin{array}{l}\text { Menjelaskan mengenai hukum air yang } \\
\text { tercemar logam berat. Dalam fiqih Islam air } \\
\text { yang tercemar logam berat dapat tergolong } \\
\text { pada dua jenis, yaitu air suci yang } \\
\text { mensucikan, dan air suci tidak mensucikan }\end{array}$ \\
\hline \multirow[t]{5}{*}{ Keracunan } & Mengkaji masalah & $\underline{\text { Hadis }}$ \\
\hline & $\begin{array}{l}\text { yang timbul dari } \\
\text { pencemaran logam } \\
\text { berat terhadap } \\
\text { keracunan mahluk }\end{array}$ & $\begin{array}{l}\text { Tahun 1900-1991 } 70 \text { orang di Manchaster, } \\
\text { serta lokasi lainnya mengalami keracunan } \\
\text { dikarenakan bir yang dikonsumsi } \\
\text { mengandung Arsen. }\end{array}$ \\
\hline & & $\begin{array}{l}\text { Bir adalah salah satu jenis khamar. Adapun } \\
\text { yang dimaksud dengan khamar yaitu } \\
\text { seluruh jenis minuman yang dapat } \\
\text { mempengaruhi pikiran sehar seseorang } \\
\text { (memabukan) , sebagaimana sabda }\end{array}$ \\
\hline & & 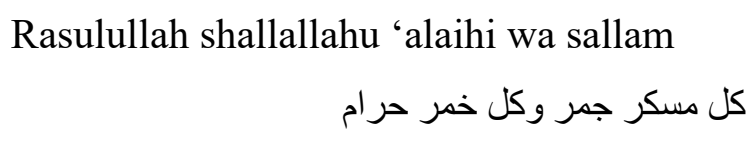 \\
\hline & & $\begin{array}{l}\text { "Setiap yang memabukkan adalah khamar } \\
\text { dan setiap khamar adalah haram" (HR } \\
\text { Muslim, 6/99) }\end{array}$ \\
\hline
\end{tabular}

B. Tahap Strukturalisai

Pada tahap strukturisasi terdapat 3 tahap yaitu 1) membuat peta konsep, 2) struktur makro, dan 3) draft bahan ajar. Berikut penjelasan setiap tahapan ini.

\section{Peta konsep}

Pada peta konsep terdapat 15 konsep yaitu logam berat, logam berat esensial, logam berat nonesensial, kegunaan logam berat, sumber pencemaran logam berat yang berasal dari kegiatan manusia dan alam, daerah pencemaran logam berat yaitu air, tanah, dan udara, efek toksik logam berat yaitu keracunan, karsinogenik, dan penyakit minamata, dan yang terakhir penanggulangan pencemaran logam berat. 


\section{Struktur makro}

Pada struktur makro terdapat 6 konsep utama yaitu, logam berat, kegunaan logam berat, sumber pencemaran logam berat, daerah pencemaran logam berat, efek toksik logam berat, dan yang terakhir penanggulangan pencemaran logam berat.

\section{Draf bahan ajar}

Setelah membuat peta konsep dan struktur makro, peneliti dapat menyesuaikan draft bahan ajar dengan struktur materi yang telah tersusun dengan sistematis. Terdapat 6 bab utama dengan beberapa sub bab, berikut draft bahan ajar yang telah tersusun secara sistematis:

A. Logam berat
a. Logam berat esensial
b. Logam berat non esensial

B. Kegunaan logam berat

C. Sumber pencemaran logam berat alami dan kegiatan manusia

D. Daerah pencemaran logam berat
a. Air
b. Tanah
c. Udara

E. Efek toksik logam berat
a. Keracunan
b. Karsinogenik
c. Penyakit minamata

F. Penanggulangan pencemaran logam berat

\section{Tahap karakterisasi}

Tahap yang ketiga yaitu tahap karakterisasi, pada hasil uji karakterisasi dapat diketahui bahwa konsep yang terdapat pada buku pengayaan ini tergolong pada tingkat keterpahaman kategori tinggi. Hasil uji karakterisasi dapat dilihat pada tabel dibawah ini.

Tabel 4 Hasil Uji Karakterisasi

\begin{tabular}{llccc}
\hline No & Label konsep & $\begin{array}{c}\text { Persentase } \\
\text { Pemahaman } \\
\text { Konsep (\%) }\end{array}$ & $\begin{array}{c}\text { Tingkat } \\
\text { Pemahaman }\end{array}$ & $\begin{array}{c}\text { Kriteria Teks } \\
\text { Konsep }\end{array}$ \\
\hline 1 & Logam Berat & $100 \%$ & Tinggi & Sangat Mudah \\
2 & Logam Berat Esensial & $100 \%$ & Tinggi & Mudah \\
\hline
\end{tabular}




\begin{tabular}{|c|c|c|c|c|}
\hline 3 & Logam Berat Tidak Esensial & $95.8 \%$ & Tinggi & Mudah \\
\hline 4 & Kegunaan Logam Berat & $91.7 \%$ & Tinggi & Mudah \\
\hline 5 & Kegiatan Manusia & $100 \%$ & Tinggi & Mudah \\
\hline 6 & Alami & $79.2 \%$ & Tinggi & Mudah \\
\hline 7 & Daerah Pencemaran Logam Berat & $94,4 \%$ & Tinggi & Mudah \\
\hline 8 & Air & $90.3 \%$ & Tinggi & Mudah \\
\hline 9 & Tanah & $98.6 \%$ & Tinggi & Sangat Mudah \\
\hline 10 & Udara & $95.8 \%$ & Tinggi & Sangat Mudah \\
\hline 11 & Efek Toksik Logam Berat & $95.8 \%$ & Tinggi & Mudah \\
\hline 12 & Keracunan Mahluk Hidup & $94.4 \%$ & Tinggi & Mudah \\
\hline 13 & Karsinogenik & $100 \%$ & Tinggi & Mudah \\
\hline 14 & Penyakit Minamata & $93.1 \%$ & Tinggi & Mudah \\
\hline 15 & $\begin{array}{l}\text { Penanggulangan Pencemaran Logam } \\
\text { Berat }\end{array}$ & $95,8 \%$ & Tinggi & Mudah \\
\hline \multicolumn{2}{|c|}{ Rata-rata } & $94,72 \%$ & Tinggi & Mudah \\
\hline
\end{tabular}

\section{Tahap reduksi}

Tahap yang keempat yaitu tahap reduksi, pada proses ini peneliti tidak melakukan tahap reduksi, karena konsep yang terdapat dalam buku pengayaan pencemaran logam berat terintegrasi keisalaman dapat dipahami dengan baik oleh mahasiswa.

\section{KESIMPULAN}

Berdasarkan penelitian yang telah dilakukan, dapat disimpulkan bahwa untuk melakukan pengintegrasian ilmu Islam dan sains dapat menggunakan metode 4-STMD (four step teaching material development). Adapun hasil yang didapatkan dari setiap tahap yaitu:

1. Tahap seleksi, pada tahap ini peneliti mendapatkan referensi utama untuk menyusun buku pengayaan yaitu karya Wahyu Widowati yang berjudul Efek Toksik Logam Pencegahan dan Penanggulangan Pencemara terbitan C.V Andi Ofset Yogyakarta tahun terbitan 2008.

2. Dan buku ini selanjutnya diayak dengan integrasi keislaman yang bersumber dari AlQur'an, hadis, fiqih dan usul fiqih, ayat kauniyah, dan sejarah Islam 
3. Peneliti mendapatkan struktur konsep kimia sebanyak 15 dari 16 konsep utama kimia terintegrasi keislaman yang tervalidasi oleh ahli.

4. Tahap karakterisasi didapatkan persentase rata-rata yang dijawab dengan benar oleh mahasiswa sebesar 94,72\%. Hal ini menunjukkan bahwa konsep pada buku pengayaan pencemaran logam berat memiliki tingkat keterpahaman yang tinggi, dan termasuk kedalam konsep yang mudah dipahami.

5. Peneliti tidak melakukan tahap reduksi dikarenakan pada tahap karakterisasi dapat diketahui bahwa mahasiswa sudah dapat memahami konsep integrasi dengan baik.

\section{DAFTAR PUSTAKA}

Akbarizan. (2014). Integrasi Ilmu. Pekan Baru Riau: Suska Press

Arifin, Sjaeful Anwar. (2015). Pengembangan Bahan Ajar IPA Terpadu Tema Udara Melalui Four Steps Teaching Material Development. Jurnal Ilmu Pendidikan Dan Pengajaran, 2 (1).

Ashri, Nurul., \& Hasanah, Lilik. (2016). Uji Keterpahaman Dan Kelayakan Bahan Ajar IPA Terpadu. Jurnal Center For Science Education, 8 (2).

Bagheri, Abolqasem. (2015). The Consideration of Physics and Chemistry Sciences in Holy Quran. J. Appl. Environ. Biol. Sci., 4 (12S), 260-265.

Departemen Agama RI. (2009). Al-Qur'an dan Terjemahnya. Bandung: PT. Sygma Examedia Arkanleema.

Fauzan. (2017). Integrasi Islam Dan Sains Dalam Kurikulum Program Studi Pendidikan Guru Mi Berbasis KKNI. Journal Of Madrasah Ibtidaiyah Education, 1(1), 1-13

Herron, J. Dudley., Cantu, Luis L., Ward, Richard., \& Srinivasan,Venu. (1977). Problems Associated with Concept Ana I ysis. Journal Science Education 61(2): 185-199.

Hendri, S., \& Setiawan, W. (2016). The Development Of Earth Quake Teaching Material For Junior High School By Four Step Teaching Materials Development Method. Jurnal Pendidikan Fisika Indonesia 6612 (1), 65-76.

Iskandar, Syahrullah. (2016). Studi Alquran Dan Integrasi Keilmuan: Studi Kasus UIN Sunan Gunung Djati Bandung. Wawasan: Jurnal Ilmiah Agama Dan Sosial Budaya. Jurnal Ilmiah Agama dan Sosial Budaya 1, (1). 
Jamal, Nur. (2017). Model-Model Integrasi Keilmuan Perguruan Tinggi Keagamaan Islam. Jurnal Kabilah, 2 No. (1).

Keputusan Rektor Universitas Islam Negeri Syarif Hidayatullah Jakarta No. 864 Tahun 2017.

Lubis, Maimun Aqsha. (2015). Effective Implementation Of The Integrated Islamic Education. Global Jurnal Al-Thaqafah, 5, (1).

Munadi, Muhammad. (2016). Integration Of Islam And Science: Study Of Two Science Pesantrens (Trensain) In Jombang And Sragen. Jurnal Pendidikan Islam. 5, (2).

Peraturan Menteri Riset, Teknologi, dan Pendidikan Tinggi Republik Indonesia. No.44 Tahun 2015, tentang Standar Nasional Pendidikan Tinggi.

Ramli, (2014). Integrasi Pendidikan Agama Islam ke dalam Mata Pelajaran Ilmu Pengetahuan Alam di Madrasah Tsanawiyah Negeri Mulawarman Banjarmasin. Jurnal Kopertais XI Kalimantan, 12 (21), 111-132.

Rifai, Nurlena., Fauzan, Sayuti Wahdi, Bahrissalim. (2014). Integrasi Keilmuan Dalam Pengembangan Kurikulum Di UIN Se-Indonesia: Evaluasi Penerapan Integrasi Keilmuan UIN Dalam Kurikulum Dan Proses Pembelajaran.. Jurnal Tarbiya, . I, (1).

Shihab, M. Quraish.(2012). Al-Lubab: Makna, Tujuan, dan pelajaran dari Surahsurah Al-Qur'an. Jakarta: Lentera Hati.

Syamsuri. B S, S Anwar \& O Sumarna. (2017). Development of Teaching Material Oxidation-Reduction Reactions through Four Steps Teaching Material Development (4S TMD). Journal of Physics: Conf. Series 895.

Sudiarti, Tety., Delilah, Gina Giftia A., Aziz, Rohmanur. (2018). Besi Dalam Al Qur'an Dan Sains Kimia (Analisis Teoritis Dan Praktis Mengenai Besi Dan Upaya Mengatasi Korosi Pada Besi). Jurnal al-Kimiya, 5 (1): 7-16 .

Suhendar, Dede. (2011). Meninjau Bukti Ilmiah Kekuatan Besi Menurut Cara Pandang Ilmu Kimia Dan Sains Yang Berkaitan Beserta Beberapa Konsekuensinya Sebagaimana Disebut Dalam Al Quran Q.S.Al Hadiid:25. Jurnal ISTEK, V (1 - 2). Suprayogo, Imam. (2012). Paradigma Pengembangan Keilmuan Di Perguruan Tinggi. Malang: UIN Malang Press.

(2012). "Implementasi Konsep Integrasi Ilmu dan Agama", http://old.uinmalang.ac.id/index.php?option $=$ com_content $\& v i e w=$ article $\& i d=2918$ :implementasi-konsep-integrasi-ilmu-dan-agama-catid=25: artikelimamsuprayogo. 2012. Accessed December 13, 2019. 08: 45. 
Tajuddin, Muhammad Saleh., \& Rofie,, Mohamad Khadafi. (2014). A New Paradigm Of Integration Between Science and Islam: An Epistemological Framework. Journal Of Islam And Science, 01, (01).

Tim Penyusun Pedoman Implementasi Integrasi Ilmu Di PTKI. (2019). Keputusan Direktur Jenderal Pendidikan Islam Nomor 2498 Tahun 2019 Tentang Pedoman Implementasi Integrasi Ilmu Di Perguruan Tinggi Keagamaan Islam. Jakarta: Direktorat Pendidikan Tinggi Keagamaan Islam Direktorat Jenderal Pendidikan Islam Kementerian Agama Republik Indonesia.

Turgut, Halil. (2016). Pre-Service Science Teachers' Perceptions About Relationship Between Religion And Science In The Context Of Their Worldviews. International Online Journal Of Educational Sciences, 8 (3), 166-179.

Undang-Undang Republik Indonesia Nomor 20 Tahun 2003 Tentang Sistem Pendidikan Nasional.

Widowati W, Sastiono A, Jusuf R. (2008). Efek Toksik Logam Pencegahan dan Penanggulangan Pencemaran. Yogyakarta: ANDI.

Yusuf, Mohamad Yasin. (2017). Epistemologi Sains Islam Perspektif Agus Purwanto. Jurnal Studi Keislaman. 17, (1). 